\title{
CANALICULAR LACERATIONS: A STUDY OF ITS DEMOGRAPHY AND EPIDEMIOLOGICAL CHARACTERISTICS IN A TERTIARY CARE CENTER OF WESTERN INDIA
}

\author{
Mehul R. Patel1, Snehal Ganatra², Purvi Bhagat ${ }^{3}$ \\ ${ }_{1}^{1}$ Resident Doctor, Department of Ophthalmology, M and J Western Regional Institute of Ophthalmology. \\ ${ }^{2}$ Resident Doctor, Department of Ophthalmology, M and J Western Regional Institute of Ophthalmology. \\ ${ }^{3}$ Associate Professor, Department of Ophthalmology, M and J Western Regional Institute of Ophthalmology.
}

\section{ABSTRACT}

\section{PURPOSE}

To analyse the demography, epidemiological data and clinical profile of canalicular lacerations in a Western Regional Institute of India.

\section{METHODS}

It was a prospective study of 220 patients from July 1, 2014 to May 30, 2016, who presented with varying eyelid lacerations and repair.

\section{RESULTS}

Two hundred and twenty patients underwent eyelid laceration repairs, of which $43(19.5 \%)$ had involvement of the canalicular system. Of these, the mean age at presentation was 25 years. There were 35 men (81.4\%) and 8 women (18.6\%). In this study, the most common cause of injury was industrial accidents in $32.6 \%$ followed by $25.6 \%$ of road traffic accidents. Among children, the most common mechanism of injury was blouse-hook injury. Lower canaliculus was involved in 26 patients (60.5\%), upper in 12 patients (27.9\%) and both in 5 patients (11.6\%). Thirty canalicular lacerations underwent stenting (Angiocatheter tube).

\section{CONCLUSION}

The results of this study provide a series of high-risk conditions causing eye injuries, which would be better avoided and we also emphasise the use of protective eye equipment.

\section{KEYWORDS}

Lid Tear, Canalicular Laceration, Canalicular Stent, Industrial Hazards.

HOW TO CITE THIS ARTICLE: Patel MR, Ganatra S, Bhagat P. Canalicular lacerations: a study of its demography and epidemiological characteristics in a tertiary care center of Western India. J. Evolution Med. Dent. Sci. 2016;5(77):5688-5690, DOI: $10.14260 /$ jemds/2016/1283

\section{INTRODUCTION}

Ocular trauma is an important cause of visual impairment worldwide. Protective mechanisms against ocular trauma are reflex closure of eyelids in response to trauma. The upward rotation of eye in response to sudden stimulus and also the cushioning effect of retrobulbar fat are also protective. Although many forms and settings of ocular trauma are preventable, ocular trauma will continue to represent a significant problem in the foreseeable future.

Eyelid lacerations are an important subtype of ocular trauma. Lesions of the lacrimal drainage system occur in up to $16 \%$ of all eyelid injuries.[1] Canalicular lacerations are the most common form of injury of lacrimal drainage system, because of their exposed position in the upper and lower lid.[2]

In children dog bites, handlebar injuries and collisions with sharp objects while running (e.g. sticks, thorns, protruding nail) comprise the most common aetiologies. $[3,4,5]$ In adolescents and adults, blunt trauma (e.g. motor vehicle collision, fist fight, sports, injury at workplace) is most frequent.[6] Males are affected more commonly than females.

Financial or Other, Competing Interest: None.

Submission 27-07-2016, Peer Review 12-09-2016,

Acceptance 19-09-2016, Published 23-09-2016.

Corresponding Author:

Dr. Mehul R. Patel,

\#5/27, Swair Vihar Society,

Panjara Pole Cross Road,

Ambavadi, Ahmedabad-380016.

E-mail: drmehulpatel311@gmail.com

DOI: $10.14260 /$ jemds/2016/1283

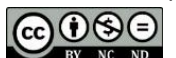

Proper management of canalicular lacerations require thorough knowledge of the anatomy of the lacrimal drainage system, eyelids and periorbital structures, careful examination for associated ocular injury and prompt referral to a team of subspecialists when complicated lacerations are encountered. Use of angiocatheter tubes as against mini monoka stents in the repair of canalicular laceration is a safe, economical and feasible alternative, especially since majority of patients presenting with such injuries are of lower socio-economic strata. The results obtained by stenting with angiocatheter tube are comparable with those obtained by stenting with mini monoka stent. [7] Improper repair leads to lifelong epiphora and also often becomes an issue of cosmetic concern.

In spite of this being one of the preventable health issues commonly seen around the world, unfortunately limited literature is available on the demography and epidemiological aspects of canalicular involvement in eyelid trauma. ${ }^{[8]}$ Further, understanding the consequences of a maltreated tear, it becomes extremely important to address this issue in order to reduce its impact on the socioeconomics of the community. ${ }^{[9]}$

\section{MATERIALS AND METHODS}

This is a prospective study carried out from July 1, 2014 to May 30, 2016 in a Tertiary Referral Care Center of Western India in 220 eyes having eyelid lacerations. All ethical aspects have been taken due care of.

This study included all patients presenting to the emergency clinic with eyelid tears and canalicular lacerations. Those patients having profound tissue loss and primarily operated elsewhere for eyelid injury were excluded. 
History and Examination included the Following

- $\quad$ Age and Sex of the patient.

- Cause and mechanism of the injury.

- Snellen's best corrected visual acuity.

- Detailed ocular examination.

- Fundus examination by indirect ophthalmoscopy.

- Imaging studies: X-Ray of skull with orbit.

After thorough evaluation, meticulous microscopic repair was done under local anaesthesia or general anaesthesia as required. The superior canaliculus was probed with lacrimal probe. A 24-G angiocatheter tube was used to cannulate the torn canaliculus. After repairing the laceration, fixation suture with 6-0 Vicryl was passed through the tube to prevent its extrusion.

Canalicular repair was usually done within 6 hours of injury, i.e. before the oedema set in or later after the oedema subsided.

Postoperative care included local antibiotic ointment application and broad-spectrum systemic antibiotics for 5 days. Patients were counselled to avoid rubbing the eyes in order to prevent extrusion of the angiocatheter tube. Angiocatheter tube was left in situ for 12 weeks.

\section{RESULTS}

Two hundred and twenty patients had eyelid lacerations, of which $43(19.5 \%)$ had involvement of the canalicular system. The age of patients varied from 3 to 75 years (Mean age - 25 years) (Table 1). There were 35 men $(81.4 \%)$ and 8 women (18.6\%) (Figure 1).

Considering the characteristics of the lacerations, the right eye was involved in 25 patients (58.1\%); the left eye was involved in 18 patients (41.9\%). Both upper and lower canalicular laceration were implicated in 5 patients $(11.6 \%)$ (Table 2).

Thus, in this study lower canaliculus was involved in 26 patients $(60.5 \%)$, upper in 12 patients $(27.9 \%)$ and both in 5 patients (11.6\%) (Figure 2, Figure 3 and Figure 4).

Among the study participants 19 worked in factories, 7 were housekeepers, 6 were farmers and the remaining 5 patients were either unemployed or retired at the time of the injury. Six patients were children.

In this study, the most common mechanism of injury was due to industrial accidents (32.6\%), mostly metallic industry followed by road traffic accidents (25.6\%). Among children, the most common mechanism of injury was blouse-hook injury during breast-feeding (Table 3 and Table 4).

Visual Acuity at presentation ranged from 6/6 - counting fingers at 3 meter with similar vision postoperatively, indicating that the lid tears did not affect the visual acuity.

\begin{tabular}{|c|c|}
\hline Age Group (Years) & No. of Patients (\%) \\
\hline $1-09$ & $4(9.3 \%)$ \\
\hline $10-19$ & $6(13.9 \%)$ \\
\hline $20-29$ & $11(25.6 \%)$ \\
\hline $30-39$ & $6(13.9 \%)$ \\
\hline $40-49$ & $7(16.3 \%)$ \\
\hline $50-59$ & $4(9.3 \%)$ \\
\hline $60-69$ & $3(7 \%)$ \\
\hline $70-79$ & $2(4.7 \%)$ \\
\hline \multicolumn{2}{|c|}{ Total } \\
\hline \multicolumn{2}{|c|}{ Table 1: Demographical Data } \\
\hline
\end{tabular}

\begin{tabular}{|c|c|c|}
\hline \multirow{3}{*}{ Right Eye } & Upper Canaliculus & $7(16.3 \%)$ \\
\cline { 2 - 3 } & Lower Canaliculus & $15(34.9 \%)$ \\
\cline { 2 - 3 } & Both & $3(6.9 \%)$ \\
\hline \multirow{3}{*}{ Left Eye } & Upper Canaliculus & $5(11.6 \%)$ \\
\cline { 2 - 3 } & Lower Canaliculus & $11(25.6 \%)$ \\
\cline { 2 - 3 } & Both & $2(4.7 \%)$ \\
\hline Total & \multicolumn{4}{|c|}{} \\
\hline \multicolumn{2}{|c|}{ Table 2: Characteristics of the Lacerations } \\
\hline
\end{tabular}

\begin{tabular}{|c|c|}
\hline Mechanism of Injury & No. of Patients \\
\hline Road Traffic Accidents & $11(25.6 \%)$ \\
\hline Industrial Accidents & $14(32.6 \%)$ \\
\hline Household Accidents & $6(13.9 \%)$ \\
\hline Assault & $5(11.6 \%)$ \\
\hline Blouse-Hook Injury & $3(7 \%)$ \\
\hline Dog Bites & $1(2.3 \%)$ \\
\hline Unknown & $3(7 \%)$ \\
\hline Total & $\mathbf{4 3}$ \\
\hline Table 3: Mechanism of Injury \\
\hline
\end{tabular}

\begin{tabular}{|c|c|}
\hline Type of Objects & No. of Patients (\%) \\
\hline Sharp Metallic Objects & $25(58.1 \%)$ \\
\hline Wooden Stick & $6(14 \%)$ \\
\hline Glass & $2(4.6 \%)$ \\
\hline Fan Blades & $1(2.3 \%)$ \\
\hline Blouse-Hook & $3(7 \%)$ \\
\hline Dog Bites & $1(2.3 \%)$ \\
\hline Others & $5(11.7 \%)$ \\
\hline \multicolumn{2}{|c|}{ Total } \\
Table 4: Type of Objects causing Injury \\
\hline
\end{tabular}

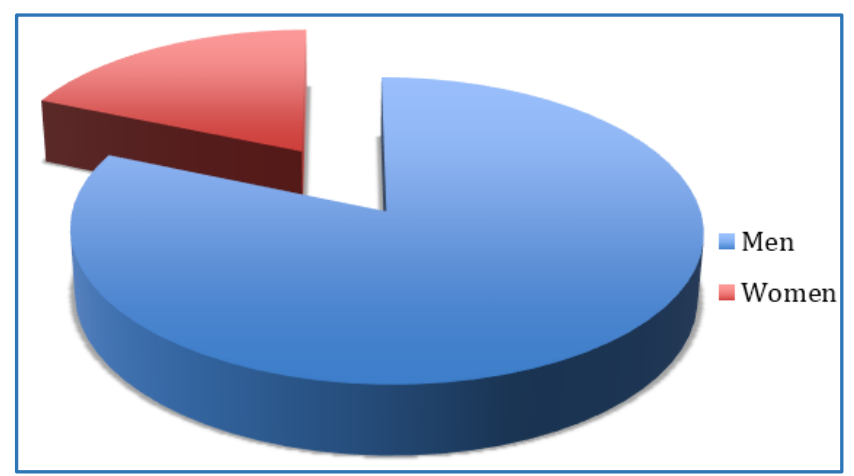

Fig. 1: Gender Distribution

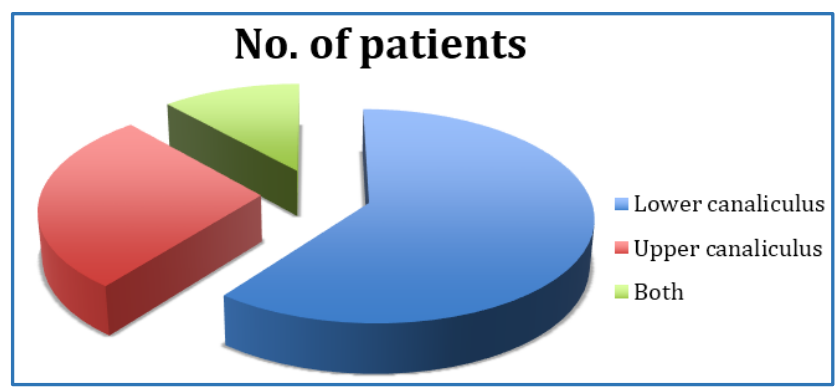

Fig. 2: Characteristics of the Lacerations 


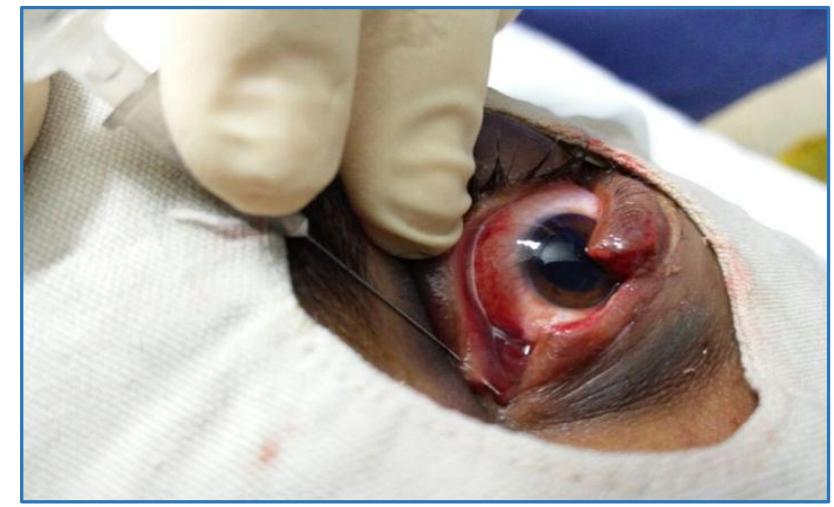

Fig. 3: Upper Canalicular Laceration

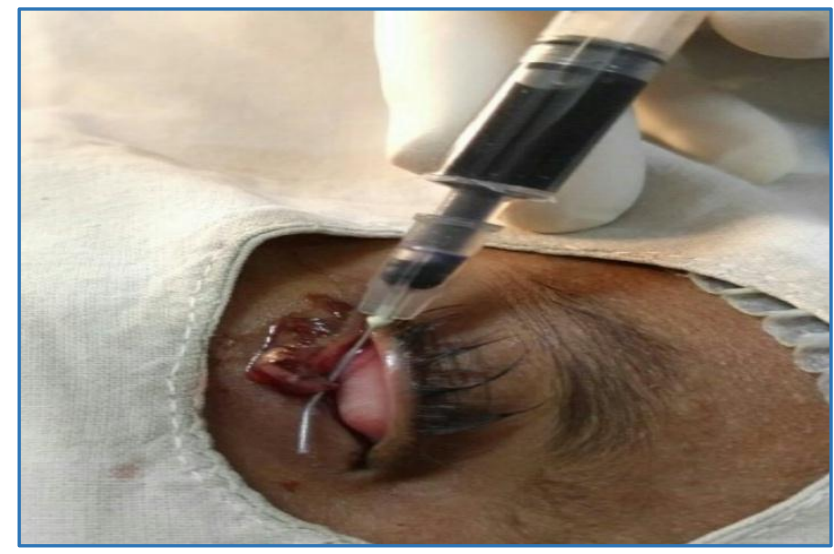

Fig. 4: Lower Canalicular Laceration

\section{DISCUSSION}

Lid trauma is a common emergency faced by ophthalmologists and lesions of the lacrimal drainage system occur in up to $16 \%$ of all eyelid injuries.[1]

Several reports described the management of canalicular lacerations with different procedures, but there is limited literature available on the demography and epidemiological aspects of canalicular involvement in eyelid trauma.[10]

In a study conducted at Iran, the results showed a greater prevalence for eyelid lacerations among male patients (75.3\%) of active age (i.e. 29 years), most of who were occupied at factories, workshops or were just workers in one form or another. This is totally consistent with other reports and also in our series ocular trauma was shown to be more prevalent among younger adults, men and even of higher incidence in less skilled workers.[11,12,13,14]

Kennedy and Associates, in an 11-year epidemiologic and clinical study have noted that two-thirds of canalicular injuries have occurred in children or young adults below 30 years of age with a median age of 20 years at the time of injury.[3] In our study, $48.8 \%$ of patients were below 30 years of age.

Kennedy and Associates have also reported lower eyelid involvement in $66.2 \%$ of cases. Our study has also shown a similar trend with the lower canaliculus being most commonly involved in $60.5 \%$ of patients. ${ }^{[3]}$ The same study reported dog bites and scratches as the most common cause of injury in children, whereas blouse-hook was the most common mode of injury among children in our series. ${ }^{[3]}$
Among victims of motor vehicle accidents, motorcycles were responsible for more than half of the reported cases. This is because people do not tend to use safety apparatus, such as a helmet while riding.[14]

\section{CONCLUSION}

This study highlights the demography of canalicular lacerations. The results of this study also provide a series of high-risk conditions, which could be easily avoided and it emphasises the use of protective glasses at workplace and safety equipment while driving. Education also needs to be given to breast-feeding mothers to avoid trivial traumas to the child, which can lead to grave lifelong consequences.

\section{REFERENCES}

1. Drnovsek-Olup B, Beltram M. Trauma of lacrimal drainage system: retrospective study of 32 patients. Croat Med J 2004;45(3):292-4.

2. Wulce AE, Arteberry JF. The pathogenesis of canalicular laceration. Ophthalmology 1991;98(8):1243-9.

3. Kennedy RH, May J, Dailey J, et al. Canalicular laceration. An 11-year epidemiologic and clinical study. Ophthal Plast Reconstr Surg 1990;6(1):46-53.

4. Reifler DM. Management of canalicular laceration. Surv Ophthalmol 1991;36(2):113-32.

5. Fannin LA, Fitch CP, Raymond WR, et al. Eye injuries from merchandise display hooks. Am J Ophthalmol 1995; 120(3):397-9.

6. Zagelbaum BM, Starkey C, Hersh PS, et al. The national basketball association eye injury study. Arch Ophthalmol 1995;113(6):749-52.

7. Tathe S, Dhaytadak P. Monocanalicular repair using angiocatheter tube as a stent in a young patient in a rural setup. Nepal J Ophthalmol 2013;5(1):106-8.

8. Whitcher JP, Srinivasan M, Upadhyay MP. Corneal blindness: a global perspective. Bull World Health Organ 2001;79(3):214-21.

9. Négrel AD, Thylefors B. The global impact of eye injuries. Ophthalmic Epidemiol 1998;5(3):143-69.

10. Herzum H, Holle $P$, Hintschich C. Eyelid injuries: epidemiological aspects. Ophthalmologe 2001;98(11): 1079-82.

11. Wong TY, Klein BE, Klein R. The prevalence and 5-year incidence of ocular trauma. The beaver dam eye study. Ophthalmology 2000;107(12):2196-202.

12. Glynn RJ, Seddon JM, Berlin BM. The incidence of eye injuries in New England adults. Arch Ophthalmol 1988; 106(6):785-9.

13. Dandona L, Dandona $\mathrm{R}$, Srinivas $\mathrm{M}$, et al. Ocular trauma in an urban population in southern India: the Andhra Pradesh eye disease study. Clin Experiment Ophthalmol 2000;28(5):350-6.

14. Tabatabaei A, Kasaei A, Nikdel $M$, et al. Clinical characteristics and causality of eye lid laceration in Iran. Oman Medical Journal 2013;28(2):97-101. 